\title{
Medical Expert Systems for Diagnosis of Various Diseases
}

\author{
Jimmy Singla \\ Research Scholar \\ IKG PTU
}

\author{
Dinesh Grover, PhD \\ Ex-Director \\ Dept. of CSE \& IT \\ LLRIET, Moga
}

\author{
Abhinav Bhandari \\ Asst. Prof. \\ Dept. of CE, UCOE \\ Punjabi University, Patiala
}

\begin{abstract}
Diseases should be treated well and on time. If they are not treated on time, they can lead to many health problems and these problems may become the cause of death. These problems are becoming worse due to the scarcity of specialists, practitioners and health facilities. In an effort to address such problems, studies made attempts to design and develop expert systems which can provide advice for physicians and patients to facilitate the diagnosis and recommend treatment of patients. This review paper presents a comprehensive study of medical expert systems for diagnosis of various diseases. It provides a brief overview of medical diagnostic expert systems and presents an analysis of already existing studies.
\end{abstract}

\section{General Terms}

Artificial intelligence, Expert system, Medical knowledge.

\section{Keywords}

Disease, Symptom, Rule, Patient.

\section{INTRODUCTION}

Artificial Intelligence is defined as brainpower exhibited by an artificial unit. It is a division of computer science dealing with sharp behavior, knowledge. Research in artificial intelligence is anxious with producing machines to computerize jobs requiring sharp actions. Examples include capability to answer diagnostic and user question, speech and facial recognition [4]. Artificial intelligence is separated into two categories. These two categories are conventional artificial intelligence and computational intelligence. Conventional artificial intelligence includes machine learning and stastical analysis. Computational intelligence includes neural networks and fuzzy systems. The other applications of artificial intelligence are automation, computer vision, artificial creativity, expert system and knowledge management [6].

The rest of the paper is organized as follows. Section 2 provides a brief introduction to Expert System, Fuzzy expert system, artificial neural network and neuro-fuzzy technique. Section 3 provides introduction to medical expert system and medical knowledge. Section 4 describes the structure of medical expert system. Section 5 describes the working of medical expert system. Section 6 presents the related work and a comparative analysis of existing studies. Finally, the discussion is concluded in Section 7.

\section{EXPERT SYSTEM}

Expert System is one of the most common applications of artificial intelligence. It is a computer program that simulates the decision and actions of a person or an association that has specialist facts and experience in a particular field. Normally, such a system contains a knowledge base containing accumulated experience and a set of rules for applying the knowledge base to each particular situation. The major features of expert system are user interface, data representation, inference, explanations etc. Advantages of expert system are increased reliability, reduced errors, reduced cost, multiple expertise, intelligent database, reduced danger etc. Disadvantages of expert system are absence of common sense and no change with changing environment.[9].

A Fuzzy Expert System is a group of membership functions and rules. These functions and rules are used to reason about data. Fuzzy expert systems are oriented toward numerical processing. It takes numbers as input, and then translates the input numbers into linguistic terms like Small, Medium and large. Then the task of Rules is to map the input linguistic terms onto similar linguistic terms describing the output. Finally, the translation of output linguistic terms into an output number is done [9].

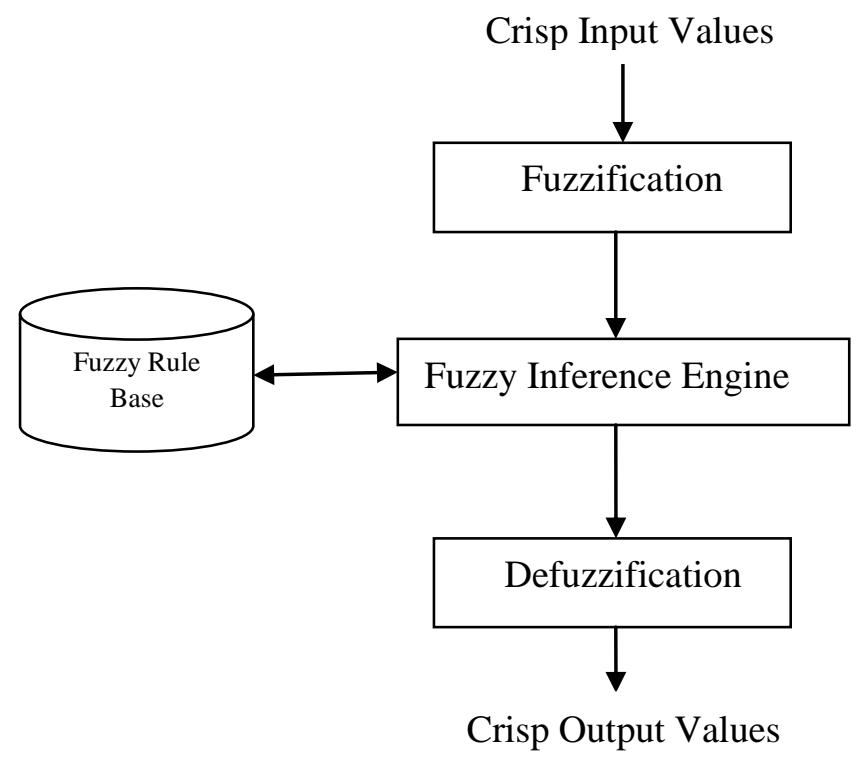

Fig. 1: Fuzzy Expert System 
Artificial Neural Network helps doctors to understand complex clinical data across a large number of medical applications. In medical application, the task is on the basis of the measured features to allocate the patient to one of a small set of classes. An artificial neural network is a computational model that tries to report for the parallel nature of the individual brain. An artificial neural network is an arrangement of extremely interconnecting processing elements operating in parallel. These elements are stirred by biological nervous systems. As in environment, the connections between basics largely find out the network function. A subgroup of processing part is called a layer in the network. The primary layer is the input layer and the final layer is the output layer. Between the input and output layer, there may be extra layers, called hidden layers [10].

\section{Input Values}

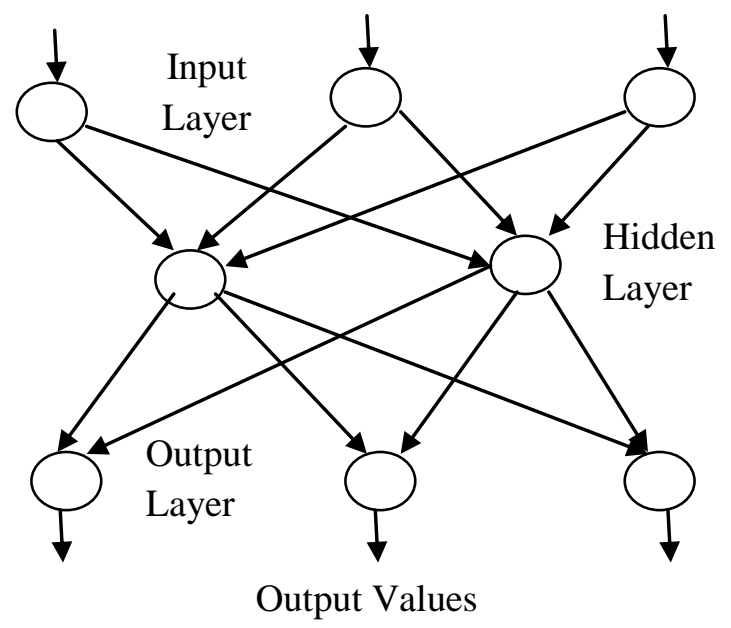

Fig. 2: A typical Neural Network [10]

A Neuro-fuzzy System is a fuzzy system that uses a learning algorithm inspired by neural network theory to determine its parameters by processing data samples [14].

\section{MEDICAL EXPERT SYSTEM}

A huge figure of expert systems is medical. The chief aim of any medical expert system is identification and cure of diseases. A medical expert system is built up of programs and medical knowledge base. The information obtained from medical expert system is similar to the information given by proficient in that particular area [6].

Medical Knowledge of specialized doctor is vital for the growth of medical expert system. This knowledge is composed in two phases. In the first phase, the medical conditions of diseases are recorded during the formation of personal meeting with doctors and patients. In the second phase, a deposit of rules is formed where each rule contains IF part that has the symptoms and THEN part that has the disease that should be realized [12].

\section{THE STRUCTURE OF MEDICAL EXPERT SYSTEMS}

A medical expert system has the following components-

1) The Knowledge Base encloses information with reference to diseases which are characterized as a set of if-then production rules. The knowledge base is analogue to the longstanding human memory. The whole sorting of production rules is prepared in the knowledge base. You may understand it with the help of example. Tuberculosis is a lung disease whose symptoms are persistent cough, constant fatigue, weight loss, loss of appetite, fever, coughing up blood, night sweats. So it will be stored in knowledge base in the form of a rule which is as follow:-

Disease (Patient, tuberculosis):-

Symptom (Patient, persistent_cough),

Symptom (Patient, constant_fatigue),

Symptom (Patient, weight_loss),

Symptom (Patient, loss_of_appetite),

Symptom (Patient, fever),

Symptom (Patient, coughing_up_blood),

Symptom (Patient, night_sweats).

\section{Fig.3: Production Rule in Knowledge Base}

Similarly in this way you can store maximum possible rules in the knowledge base.

2) The Fact Base contains facts which are applied to match in opposition to the antecedent part of rules stored in the knowledge base. The fact base is analogue to the instant human memory.

3) The foremost job of Inference Engine is to bring out the reasoning by connecting the rules with facts and deducing new facts.

4) The User Interface is used to correspond among user and expert system.

5) The Explanation Module permits the user to inquire the expert system how a finicky conclusion is reached and why a specific fact is desired.

6) The Developer Interface is used to alter the knowledge base

\section{WORKING OF MEDICAL EXPERT SYSTEMS}

In the fig. 4 the simulation of medical expert system is presented. In the figure, S1 D1 denotes the first symptom of first disease. In general Si Dj denotes the "ip" symptom of " $\mathrm{j}$ " disease. If the program has a positive answer to the symptom, it goes on with the symptoms from that disease. If a symptom from that disease is negative, it jumps to the first symptom from the next disease.

\section{RELATED WORKS}

The Medical diagnostic Systems have undergone many changes and are using new techniques to generate better results. This section briefly summarizes some of the fuzzy logic, rule based and artificial neural network based medical diagnostic systems and presents a comparative analysis of various existing studies in table 5 .

Mohammed Abbas Kadhim, M. Afshar Alam, Harleen Kaur [9] build up a fuzzy expert system for judgment of back pain diseases based on the experimental examination symptoms using fuzzy rules. The user has to key in parameters such as body mass index, age, gender of patient and experimental examination symptoms for this fuzzy expert system. On the basis of these parameters, this fuzzy expert system makes suitable judgment of back pain diseases and gives some medical suggestion to the patient. The accuracy achieved from this fuzzy expert system was $90 \%$. 


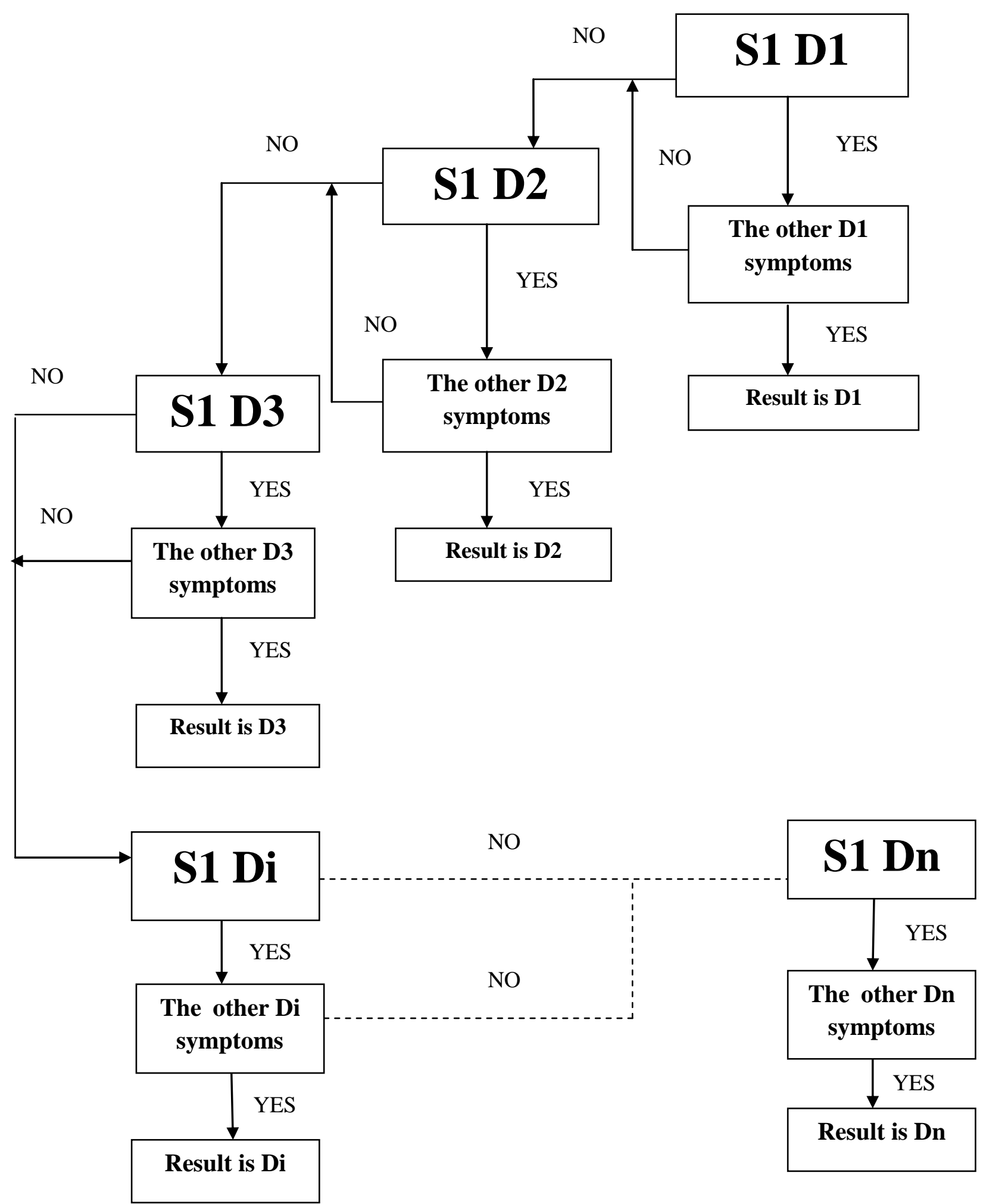

Fig. 4: Working of Medical Expert System [4] 
The classification of input variables in this expert system is done as follow:-

Table 1: Classification of Input Variables [9]

\begin{tabular}{|c|c|c|}
\hline $\begin{array}{c}\text { Input } \\
\text { Variable }\end{array}$ & Range & Fuzzy Sets \\
\hline \multirow{2}{*}{ Age } & $<25$ & Young \\
\cline { 2 - 3 } & $22-40$ & Middle \\
\cline { 2 - 3 } & $38>$ & Old \\
\hline \multirow{7}{*}{ BMI } & $<18$ & Low \\
\cline { 2 - 3 } & $19-25$ & Medium \\
\cline { 2 - 3 } & $24>$ & Hgh \\
\hline \multirow{7}{*}{ Symptom } & $<20$ & Low \\
\cline { 2 - 3 } & $18-60$ & Medium \\
\cline { 2 - 3 } & $58-80$ & High \\
\cline { 2 - 3 } & $78>$ & Very High \\
\hline
\end{tabular}

Qeethara Kadhim AI-Shayea [10] evaluate artificial neural network in diagnosis of diseases. Two cases were considered. The first one was acute nephritis disease; data was the disease symptoms. The second was the heart disease; data was on cardiac Single Proton Emission Computed Tomography images. Each patient classified into two categories: infected and non-infected. Categorization is an important tool in medical diagnosis decision support. Feed-forward back propagation neural network is applied as a classifier to distinguish between infected or non-infected person in both cases. In the diagnosis of acute nephritis disease; the percent correctly classified in the model sample by the feed-forward back propagation network is 99 percent while in the finding of heart disease; the percent correctly classified in the model sample by the feed-forward back propagation network is 95 percent. The analysis variables of data set used in this study are shown in table 2

Table 2: Diagnosis Variables of data set [10]

\begin{tabular}{|c|}
\hline Diagnosis Variable Name \\
\hline Temperature of Patient $\{35 \mathrm{C}-42 \mathrm{C}\}$ \\
\hline Occurrence of Nausea $\{$ Yes or No $\}$ \\
\hline Lumbar Pain $\{$ Yes or No $\}$ \\
\hline Urine Pushing $\{$ Yes or No $\}$ \\
\hline Micturition Pains $\{$ Yes or No $\}$ \\
\hline Burning of Urethra, itch, swelling of urethra outlet \\
$\{$ Yes or No $\}$ \\
\hline
\end{tabular}

Eugene Roventa, George Rosu [4] enlarged an expert system which is applied to detect major kidney diseases. The diagnosis is made using the readings obtained from clinical exam and the paraclinical exam. This system helps the medical expert in making the suitable analysis of a patient. A lot of common symptoms often occur in kidney diseases and many of them are alike, and that makes it difficult even for a kidney doctor to place an exact diagnosis. This expert system eliminates this trouble. This expert system has a very wellbuilt knowledge base. It has knowledge of twenty seven diseases from nine dissimilar categories.

K.Abdelhamied, S.Hafez, W.Abdalla, H.Hiekal, A.Adel [8] developed an expert system to aid health employees working in crowded outpatient clinics in Egypt make quick and perfect judgment. In this system, the medical knowledge of more than 300 major and minor common diseases is encoded in the form of production rules. These rules are invoked in collections according to one or more presenting symptoms and diagnostic hypotheses are devised for the diseases most expected to reason these symptoms. Once a disease is identified, recommendation is given for cure. The system will be assessed in 10 outpatient clinics.

Solomon Gebremariam [13] built up a prototype self-learning knowledge-based system that can offer advice for physicians and patients to assist the diagnosis and cure of diabetic patients. Knowledge is obtained using both structured and unstructured interviews from domain experts which are chosen using purposive sampling technique from Black Lion Hospital Diabetes Center. It brings into play backward chaining which initiates with possible solutions and tries to assemble information that verifies the result. The general total performance of the prototype system is $84.2 \%$. The assessments taken in this expert system are shown as follow:-

Table 3: Decision taken in Expert System [13]

\begin{tabular}{|c|c|c|}
\hline \multicolumn{2}{|c|}{ Symptoms } & Result \\
\hline \multicolumn{2}{|c|}{ Non Related Symptoms } & $\begin{array}{c}\text { Less Likely to } \\
\text { have Diabetes }\end{array}$ \\
\hline Related & $\begin{array}{c}\text { Lab Result using } \\
\text { FPG } 100-125 \\
\mathrm{mg} / \mathrm{dL}\end{array}$ & Prediabetes \\
\hline Related & $\begin{array}{c}\text { Lab Result using } \\
\text { Symptoms }\end{array}$ & Diabetes Free \\
\hline Related & Lab Result using & $\mathrm{mg} / \mathrm{dL}$ \\
Symptoms & FPG $>126 \mathrm{mg} / \mathrm{dL}$ & $\begin{array}{c}\text { Type 1/ Type 2 / } \\
\text { other Diabetes } \\
\text { type }\end{array}$ \\
\hline
\end{tabular}

Dr. Sandeep Pachpande, Ramesh Mahadik [2] planned and put into operation a medical expert system for the diagnosis of some Pulmonary Disorders. One of the endings accomplished throughout the route of this research was that the process of knowledge acquisition is a continuous process and for this reason an expert system cannot be made in a single pass fashion - an incremental approach is certain.

S Ali, P Chia, K Ong [11] present an automated delivery system for clinical guidelines (DSCG) that supports clinicians in diagnosing and treating patients bearing from chest pain in the emergency department. Strategies are adaptively selected from a knowledge base server that has a library of clinically defined, graphical guidelines. The system acquires patient data, such as illness and assessment results, and matches these 
data with eligibility criteria. It recommends most favorable treatment plans and analysis based on the most feasible diagnosis. Clinicians may either use the recommendations as a suggestion or trigger a selection to check the patient's circumstance during the cure using an intelligent agent.

Ede Kekes, Istvar Laczay, Janos Barcsak, Peter Kcch, Zoltan Antaloczy [3] developed an expert system for the valuation of the analysis and therapy ischemic heart disease in a decision model. It works in 2 different manners:

1. As a system facilitating the effective work or screening the population for IHD.

2. As an instructing model in the university and postgraduate medical education schools. It is executed in turbo prolog.

John G. Holmen, Anthony H. Walff [7] proposed an expert system that offers advice about oliguria arising on the Intensive Care Unit. Justifications are raised by discovering probable paths in a causal network of physiological states. The expert system shell expanded for this purpose is written in Prolog and runs on the IBM PC. Investigative deeds are scheduled using an schema and may be suspended and continued as required. Although the shell is wide-ranging, it maintains the definition of knowledge representation languages tailored to a fussy application. This competence is applied to build a frame notation for the representation of physiological states.

Freasier, R.E, Cios, K.J, Goodenday, L.S [5] constructed a medical expert system using the multiplication model of support logic programming so as to establish the predominant stenosis in one of the three main coronary arteries. The features taken in the determination of the analysis were data got from preprocessed scintigraphic myocardial perfusion images of the left ventricle in use in three views: anterior, left lateral and left lateral frontal oblique. Stress thallium-201 planar scintigrams from long-sufferings who had coronary arterial stenosis confirmed by coronary arteriography included the data set used for this reading. A prolog-based system was put up to discover the knowledge base so as to find out the site of the predominant stenosis. With the current set of production rules, the system properly recognized the site of coronary artery stenosis in over $90 \%$ of the long-sufferings taken into account.

Jimmy Singla [6] developed an expert system to identify the most important lung diseases between the patients. The judgment is made using the symptoms that can be felt by the patient. This medical expert system aids the doctor or expert in building the proper diagnosis of the patient. The lung diseases have many regular symptoms and some of them are very much alike. This creates much complicatedness for the physician to reach at a right conclusion. This expert system can take away this complicatedness and it is having acquaintance of thirty-two lung diseases. Its correctness is $70 \%$.

Samy S. Abu Naser, Abu Zaiter A. Ola [12] developed an expert system that urges the patient with conditions for suitable analysis of some of the eye diseases. The eye has always been viewed as a tunnel to the inner workings of the body. The disease states frequently generate symptoms from the eye. CLIPS language is used as a tool for drawing expert system. A preliminary evaluation of the expert system was passed out and a optimistic response was acknowledged from the users.

Ahmad A, Al-Hajji [1] presented a Rule-Based Expert System for Neurological Disorders. This system diagnoses and treats more than 10 types of neurological diseases. It helps the patients to acquire the required recommendation regarding the unusual disorders attack to them due to their nervous system disorders. The expert rules were built up on the symptoms of each type of neurological disease, and they were offered using decision tree and deduced using backward-chaining technique. The knowledge base contains information, gathered from volumes and practitioners about neurology and its disorders.

Table 4: Diseases diagnosed in Expert System [1]

\begin{tabular}{|c|l|}
\hline S No. & \multicolumn{1}{|c|}{ Name of Disease } \\
\hline 1 & Meningitis \\
\hline 2 & Cerebral palsy \\
\hline 3 & Migraine \\
\hline 4 & Cluster headache \\
\hline 5 & Stroke \\
\hline 6 & Epilepsy \\
\hline 7 & Multiple sclerosis \\
\hline 8 & Parkinson \\
\hline 9 & Alzheimer \\
\hline 10 & Huntington disease \\
\hline
\end{tabular}

Table 5: Comparison of Existing Studies on Medical Expert Systems

\begin{tabular}{|c|l|l|l|l|}
\hline \multicolumn{1}{|c|}{ Reference } & \multicolumn{1}{|c|}{$\begin{array}{c}\text { Disease } \\
\text { Diagnosed }\end{array}$} & Technique Used & \multicolumn{1}{|c|}{ Remarks } \\
\hline $\begin{array}{l}\text { Mohammed Abbas } \\
\text { Kadhim, M. Afshar } \\
\text { Alam, Harleen Kaur [9] }\end{array}$ & Back Pain Disease & $\begin{array}{l}\text { Fuzzy Expert } \\
\text { System }\end{array}$ & $\begin{array}{l}\text { This system is tested using } \\
\text { Body mass index, age, } \\
\text { gender and clinical data } \\
\text { observation symptoms }\end{array}$ & $\begin{array}{l}\text { 20 patients with different back } \\
\text { pain diseases and 90\% accuracy is } \\
\text { achieved. }\end{array}$ \\
\hline
\end{tabular}




\begin{tabular}{|c|c|c|c|c|}
\hline Reference & $\begin{array}{c}\text { Disease } \\
\text { Diagnosed }\end{array}$ & Technique Used & Input & Remarks \\
\hline \multirow{2}{*}{$\begin{array}{l}\text { Qeethara Kadhim AI- } \\
\text { Shayea [10] }\end{array}$} & $\begin{array}{l}\text { Acute Nephritis } \\
\text { Disease }\end{array}$ & \multirow{2}{*}{$\begin{array}{l}\text { Artificial Neural } \\
\text { Network }\end{array}$} & Disease symptoms & $\begin{array}{l}99 \% \text { accuracy is achieved in } \\
\text { diagnosis of Acute Nephritis } \\
\text { Disease. }\end{array}$ \\
\hline & Heart Disease & & $\begin{array}{l}\text { Data is on Cardiac } \\
\text { single proton emission } \\
\text { computed tomography } \\
\text { images }\end{array}$ & $\begin{array}{l}95 \% \text { accuracy is achieved in } \\
\text { diagnosis of heart disease using } \\
\text { feed forward back propagation } \\
\text { network. }\end{array}$ \\
\hline $\begin{array}{l}\text { Eugene Roventa, } \\
\text { George Rosu [4] }\end{array}$ & Kidney Disease & $\begin{array}{l}\text { Rule based Expert } \\
\text { System }\end{array}$ & Disease symptoms & $\begin{array}{l}\text { This system contains knowledge } \\
\text { of } 27 \text { kidney diseases but no } \\
\text { experimental results are found. }\end{array}$ \\
\hline $\begin{array}{l}\text { K.Abdelhamied, } \\
\text { S.Hafez, W.Abdalla, } \\
\text { H.Hiekal, A.Adel [8] }\end{array}$ & $\begin{array}{l}\text { Major and Minor } \\
\text { Diseases }\end{array}$ & $\begin{array}{l}\text { Rule based Expert } \\
\text { System }\end{array}$ & Disease symptoms & $\begin{array}{l}\text { The system contains knowledge } \\
\text { of } 300 \text { major and minor diseases. } \\
\text { It is being evaluated in } 10 \\
\text { outpatient clinics but no } \\
\text { experimental results are given. }\end{array}$ \\
\hline $\begin{array}{l}\text { Solomon Gebremariam } \\
\text { [13] }\end{array}$ & Diabetes Disease & $\begin{array}{l}\text { Rule based Expert } \\
\text { System }\end{array}$ & $\begin{array}{l}\text { Disease Symptoms, Lab } \\
\text { test results, Age, Family } \\
\text { history, obesity, Ketone }\end{array}$ & $\begin{array}{l}\text { This system provides advice to } \\
\text { physicians and patients to } \\
\text { facilitate the diagnosis and } \\
\text { treatment of diabetes the } \\
\text { Performance of the system is } \\
84.2 \% \text {. }\end{array}$ \\
\hline $\begin{array}{l}\text { Sandeep Pachpande, } \\
\text { Ramesh Mahadik [2] }\end{array}$ & $\begin{array}{l}\text { Pulmonary } \\
\text { disorders }\end{array}$ & $\begin{array}{l}\text { Rule based Expert } \\
\text { System }\end{array}$ & Disease Symptoms & $\begin{array}{l}\text { This expert system shows that } \\
\text { construction of expert system is } \\
\text { not a single pass fashion. It is an } \\
\text { incremental approach. No } \\
\text { experimental results of this expert } \\
\text { system are found. }\end{array}$ \\
\hline $\begin{array}{l}\text { S.Ali, P. Chia, } \\
\text { K Ong [11] }\end{array}$ & Chest Pain & $\begin{array}{l}\text { Knowledge Based } \\
\text { System }\end{array}$ & $\begin{array}{l}\text { Data obtained from } \\
\text { Laboratory } \\
\text { Examinations, Chest X- } \\
\text { Ray images, Ultrasound } \\
\text { Video, Narrative texts } \\
\text { describing the patient's } \\
\text { condition }\end{array}$ & $\begin{array}{l}\text { This expert system delivers } \\
\text { appropriate clinical guidelines and } \\
\text { is finalized for pilot trial at the } \\
\text { accidents and emergency } \\
\text { department of the national } \\
\text { university hospital. No } \\
\text { experimental results of this expert } \\
\text { system are found. }\end{array}$ \\
\hline $\begin{array}{l}\text { John G. Holmen, } \\
\text { Anthony H. Walff [7] }\end{array}$ & $\begin{array}{l}\text { Oliguria occurring } \\
\text { on the Intensive } \\
\text { Care Unit }\end{array}$ & $\begin{array}{l}\text { Knowledge Based } \\
\text { System }\end{array}$ & $\begin{array}{l}\text { Central Venous } \\
\text { Pressure }\end{array}$ & $\begin{array}{l}\text { This system gives advice about } \\
\text { oliguria occurring on intensive } \\
\text { care unit and no experimental } \\
\text { results are shown. }\end{array}$ \\
\hline
\end{tabular}




\begin{tabular}{|c|c|c|c|c|}
\hline Reference & $\begin{array}{c}\text { Disease } \\
\text { Diagnosed }\end{array}$ & Technique Used & Input & Remarks \\
\hline $\begin{array}{l}\text { Freasier, R.E, Cios, K.J, } \\
\text { Goodenday, L.S [5] }\end{array}$ & $\begin{array}{l}\text { Predominant } \\
\text { Coronary Arterial } \\
\text { Stenosis }\end{array}$ & $\begin{array}{l}\text { Knowledge Based } \\
\text { System }\end{array}$ & $\begin{array}{l}\text { Data obtained from } \\
\text { preprocessed } \\
\text { scintigraphic } \\
\text { myocardial perfusion } \\
\text { images of the left } \\
\text { ventricle taken in three } \\
\text { views }\end{array}$ & $\begin{array}{l}\text { This system determines the site of } \\
\text { the predominant stenosis. With } \\
\text { the current set of production rules, } \\
\text { the system properly recognized } \\
\text { the site of coronary artery stenosis } \\
\text { in over } 90 \% \text { of the patients } \\
\text { presented. }\end{array}$ \\
\hline Jimmy Singla [6] & Lung Diseases & $\begin{array}{l}\text { Rule based Expert } \\
\text { System }\end{array}$ & Disease symptoms & $\begin{array}{l}\text { This expert system contains } \\
\text { knowledge of } 32 \text { lung diseases } \\
\text { and the system has } 70 \% \text { accuracy. }\end{array}$ \\
\hline $\begin{array}{l}\text { Samy S. Abu Naser, } \\
\text { Abu Zaiter A. Ola [12] }\end{array}$ & Eye Diseases & $\begin{array}{l}\text { Knowledge Based } \\
\text { System }\end{array}$ & Disease symptoms & $\begin{array}{l}\text { The proposed system can help } \\
\text { doctors and patients in providing } \\
\text { decision support system, } \\
\text { interactive training tool and expert } \\
\text { advice. A number of doctors and } \\
\text { patients tested the system and } \\
\text { gave a positive feedback but no } \\
\text { parameters are calculated for this } \\
\text { expert system. }\end{array}$ \\
\hline Ahmad A, Al-Hajji [1] & $\begin{array}{l}\text { Neurological } \\
\text { Disorders }\end{array}$ & $\begin{array}{l}\text { Rule based Expert } \\
\text { System }\end{array}$ & Disease symptoms & $\begin{array}{l}\text { This expert system helps the } \\
\text { patients to get the required advice } \\
\text { about the different disorders } \\
\text { attack to them due to their } \\
\text { nervous system disorders. Since } \\
\text { No parameters are retrieved. }\end{array}$ \\
\hline $\begin{array}{l}\text { Obi J.C, Imianvan A.A } \\
{[16]}\end{array}$ & Leukemia & $\begin{array}{l}\text { Neuro-Fuzzy } \\
\text { Expert System }\end{array}$ & Disease symptoms & $\begin{array}{l}\text { This expert system tells the } \\
\text { patient his current condition as } \\
\text { regards leukemia. No parameters } \\
\text { are retrieved for this expert } \\
\text { system. }\end{array}$ \\
\hline
\end{tabular}

\section{CONCLUSIONS}

This review paper describes different expert systems in medical diagnosis and evaluates the contributions made by different researchers. Some researchers have evaluated their medical expert systems in hospitals from the experts and retrieved various parameters like accuracy and precision. Using these parameters, they have calculated the performance of their expert systems. The accuracy and other parameters of expert system depend on the knowledge base. The knowledge base should have relevant knowledge. There should be stress on knowledge acquisition, a stage in which knowledge is gathered. So performance of expert system depends on all these factors. One can increase the performance of expert system by making knowledge base more accurate and very little work is done using neuro-fuzzy, ANN and fuzzy logic in medical diagnosis. So we will go for these in medical diagnosis.

\section{ACKNOWLEDGEMENTS}

Jimmy Singla Author wants to express his sincere thanks to Dr. Dinesh Grover, Ex-Director, Lala Lajpat Rai Institute of Engg. \& Tech. Moga , Prof. Abhinav Bhandari, Punjabi University, Patiala , his Parents Er. Rajiv Singla, Sub Divisional Engineer \& Mrs. Bindu Singla, Er. Nikita, Asst.
Prof., MMU Ambala for guiding him at every step in his career.

\section{REFERENCES}

[1] Ahmad A. Al-Hajji, "Rule Based Expert System for Diagnosis and Symptom of Neurological disorders", proceedings of ICCIT 2012.

[2] Dr. Sandeep Pachpande, Ramesh Mahadik, "Expert System for Diagnosis of Pulmonary Disorders", ASM's International E-Journal of Ongoing Research in Management and IT, INCON 13-IT-018, pp 01-08.

[3] Ede Kekes, Istvar Laczay, Janos Barcsak, Peter Koch, Zoltan Antaloczy, "CORONARIA Expert System for Diagnosis and Therapy of Ischemic Heart Disease", proceedings of IEEE Engineering in Medicine \& Biology Society tenth Annual International Conference 1988 IEEE.

[4] Eugena Roventa, George Rosu, "The Diagnosis of Some Kidney Diseases in a PROLOG Expert System", proceedings of the third international workshop on Soft Computing Applications 2009 IEEE. 
[5] Freasier, R. E, Cios, K. J, Goodenday, L.S, "Determination of Predominant Coronary Arterial Stenosis by a Knowledge Based System", proceedings of IEEE Engineering in Medicine \& Biology Society tenth Annual International Conference 1988 IEEE.

[6] Jimmy Singla, "The Diagnosis of Some Lung Diseases in a PROLOG Expert System", International Journal of Computer Applications, vol. 78, no. 15, pp. 37-40, September 2013.

[7] John G. Holman, Anthony H. Walff, "An Expert Driver for OLIGURIA occurring on the Intensive Care Unit", proceedings of IEEE Engineering in Medicine \& Biology Society tenth Annual International Conference 1988 IEEE.

[8] K. Abdelhamied, S. Hafez, W. Abdalla, H. Hiekal, A. Adel, " A Rule - Based Expert System for Rapid Problem Solving in Crowded Outpatients Clinics in EGYPT", proceedings of the IEEE Engineering in Medicine \& Biology Society tenth Annual International Conference 1988 IEEE.

[9] Mohammed Abbas Kadhim, M. Afshar Alam, Harleen Kaur, "Design and Implementation of Fuzzy expert System of Back Pain Diagnosis", International Journal of Innovative technology \& Creative Engineering, vol. 1, no. 9, pp16-22, September 2011.

[10] Qeethara Kadhim AI - Shayea, "Artificial Neural Networks in Medical Diagnosis", IJCSI International Journal of Computer Science Issues, vol. 8, issue 2, pp 150-154, march 2011.

[11] S Ali, P Chia, K Ong, "Graphical Knowledge - Based Protocols for Chest Pain Management" proceedings of the Computers in Cardiology 1999 IEEE.
[12] Samy S. Abu Naser, Abu Zaiter A. Ola, "An Expert System for Diagnosing Eye Diseases Using CLIPS", Journal of Theoretical and Applied Information Technology, pp. 923-930, 2005-2008 JATIT.

[13] Solomon Gebremariam, "A Self Learning Knowledge Based System for Diagnosis and Treatment of Diabetes", Master's thesis, Addis Ababa University, Ethiopia.

[14] Arshdeep Kaur, Amrit Kaur "Comparison of fuzzy logic and neuro fuzzy algorithms for air conditioning system" international journal of soft computing and engineering, vol. 2, issue 1, march 2012.

[15] S. M. Kamruzzaman, Ahmed Ryadh hasan, Abu Bakar siddiquee, Md. Ehsanul Hoque mazumder "Medical diagnosis using neural network", proceedings of the third international conference on electrical and computer engineering December 2004.

[16] Obi J.C, Imianvan A.A "Interactive neuro-fuzzy expert system for diagnosis of leukemia", global journal of computer science and technology vol. 11, issue 12 , version 1.0 , july 2011

\section{AUTHOR'S PROFILE}

Jimmy Singla is Assistant Professor at Punjab Institute of Technology, Hoshiarpur, a constituent institute of Punjab Technical University Jalandhar. He has received his B.Tech and M.Tech in Computer Science \& Engg. From LLRIET, Moga. He is now pursuing Ph.D in Computer Engg. From Punjab Technical University Kapurthala. His areas of interest are fuzzy logic, expert systems and digital image processing. He has to his credit many papers in national, international journals and conferences and a book on asynchronous transfer mode. 